\title{
Near-field pollutant dispersion in an actual urban area: analysis of the mass transport mechanism by high- resolution Large Eddy Simulations
}

\author{
P. Gousseau ${ }^{a}$, B. Blocken* a,b ${ }^{\text {a, T. Stathopoulos }}{ }^{\text {c }}$, G.J.F. van Heijst ${ }^{\text {d }}$ \\ ${ }^{a}$ Building Physics and Services, Eindhoven University of Technology, P.O. Box 513, 5600 MB Eindhoven, \\ the Netherlands \\ ${ }^{\mathrm{b}}$ Building Physics Section, Department of Civil Engineering, Leuven University, Kasteelpark Arenberg $40-$ \\ bus 2447, 3001 Leuven, Belgium \\ ${ }^{\mathrm{c}}$ Building, Civil and Environmental Engineering, Concordia University, 1455 Blvd. de Maisonneuve West, \\ Montreal, Quebec, Canada, H3G 1 M8 \\ ${ }^{\mathrm{d}}$ Fluid Dynamics Laboratory, Department of Physics, Eindhoven University of Technology, P.O. Box 513, \\ $5600 \mathrm{MB}$ Eindhoven, the Netherlands
}

\section{Graphical abstract}

Pollutant dispersion in downtown Montreal seen as the transport by the mean flow and by the turbulent fluctuations

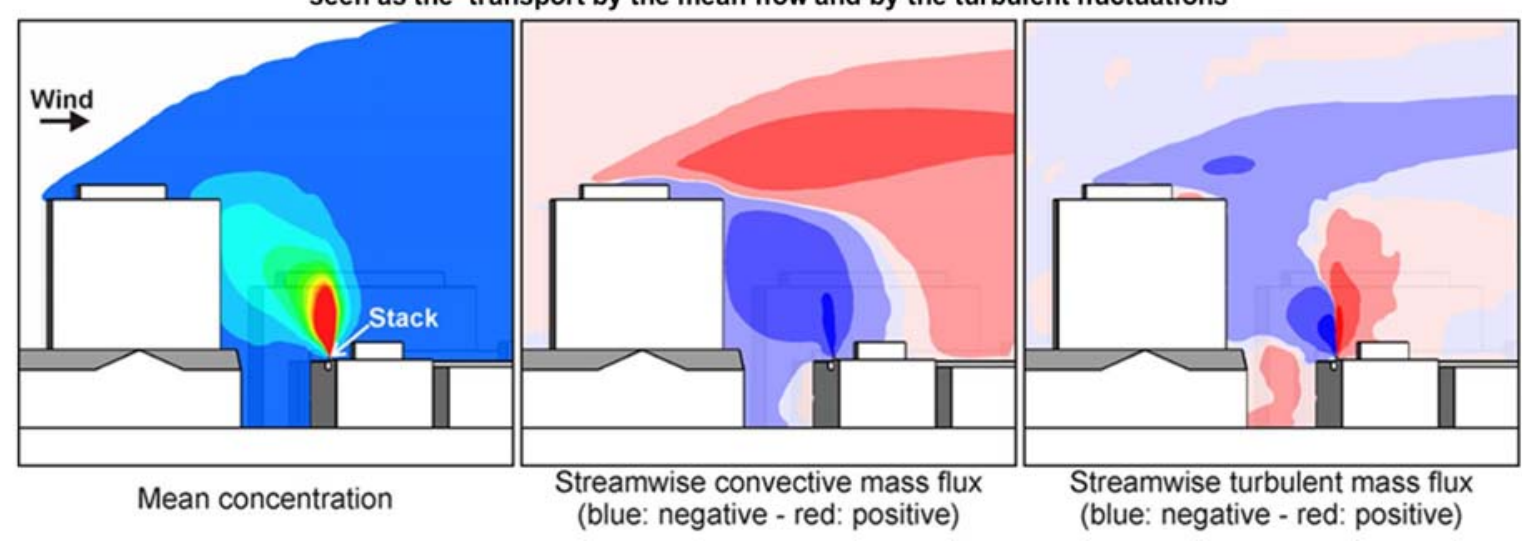

\section{Highlights}

- $\quad$ Pollutant dispersion in downtown Montreal is studied with high-resolution LES.

- The contribution of the sub-grid scales to turbulent mass transport is minor in this case.

- The results of this applied case are linked to those obtained for a generic isolated building.

- $\quad$ The counter gradient mechanism of turbulent mass transport is observed.

- With RANS, the turbulent flux model used should be able to reproduce this mechanism.

\footnotetext{
* Corresponding author: Bert Blocken, Building Physics and Services, Eindhoven University of Technology, P.O.Box 513, 5600 MB Eindhoven, the Netherlands. Tel.: +31 (0)40 247 2138, Fax +31 (0)40 2438595 E-mail address: b.j.e.blocken@tue.nl
} 


\title{
Near-field pollutant dispersion in an actual urban area: analysis of the mass transport mechanism by high- resolution Large Eddy Simulations
}

\author{
P. Gousseau ${ }^{\mathrm{a}}$, B. Blocken* ${ }^{\mathrm{a}, \mathrm{b}}$, T. Stathopoulos ${ }^{\mathrm{c}}$, G.J.F. van Heijst ${ }^{\mathrm{d}}$ \\ ${ }^{a}$ Building Physics and Services, Eindhoven University of Technology, P.O. Box 513, 5600 MB Eindhoven, \\ the Netherlands \\ ${ }^{\mathrm{b}}$ Building Physics Section, Department of Civil Engineering, Leuven University, Kasteelpark Arenberg 40 - \\ bus 2447, 3001 Leuven, Belgium \\ ${ }^{\mathrm{c}}$ Building, Civil and Environmental Engineering, Concordia University, 1455 Blvd. de Maisonneuve West, \\ Montreal, Quebec, Canada, H3G $1 M 8$ \\ ${ }^{\mathrm{d}}$ Fluid Dynamics Laboratory, Department of Physics, Eindhoven University of Technology, P.O. Box 513, \\ 5600 MB Eindhoven, the Netherlands
}

\begin{abstract}
Large-Eddy Simulation of near-field pollutant dispersion from stacks on the roof of a low-rise building in downtown Montreal is performed. Two wind directions are considered, with different wind-flow patterns and plume behavior. The computed mean concentration field is analyzed by means of the convective and turbulent (including subgrid-scale) mass fluxes. This decomposition provides insight into the dispersion process and allows an evaluation of common turbulent transport models used with the Reynolds-Averaged Navier-Stokes approach, such as the standard gradient-diffusion hypothesis. Despite the specific character of the flow and dispersion patterns due to the complex geometry of the urban area under study, some similarities are found with the generic case of dispersion around an isolated simple building. Moreover, the analysis of dispersion in downtown Montreal is facilitated by the physical insight gained by the study of the generic case. In this sense, the present study supports the use of generic, simplified cases to investigate and understand environmental processes as they occur in real and more complex situations. Reciprocally, the results of this applied study show the influence on the dispersion process of the rooftop structures and of the orientation of the emitting building with respect to the incoming wind flow, providing directions for further research on generic cases.
\end{abstract}

\section{Keywords}

Computational Fluid Dynamics (CFD); Large-Eddy Simulation (LES); Urban physics; Scalar transport; Wind flow; Turbulence modeling.

\section{Introduction}

Outdoor air pollution is one of the major environmental problems today. Urban areas are characterized by a wide range of pollutant sources such as building HVAC systems, traffic, industry, etc. Urban air pollution is associated with a broad spectrum of acute and chronic health effects [1]. The present paper focuses on the socalled near-field pollutant dispersion, which refers to local emission sources and dispersion of these emissions at the scale of nearby individual buildings up to neighborhoods.

Urban wind flow and pollutant dispersion can be assessed by field measurements, reduced-scale wind-tunnel experiments or numerical simulation with Computational Fluid Dynamics (CFD). Each method has its particular advantages and disadvantages. Full-scale measurements can suffer from the inherently uncontrollable and unsteady meteorological conditions [2-4]. In addition, they are usually only performed at a few discrete positions in space and do not provide a whole image of the flow field. Reduced-scale experiments in atmospheric boundary layer (ABL) wind tunnels allow full control over the initial and boundary conditions of the experiments, but are generally also only performed at a few selected points in the urban model. In addition,

\footnotetext{
* Corresponding author: Bert Blocken, Building Physics and Services, Eindhoven University of Technology, P.O.Box 513, 5600 MB Eindhoven, the Netherlands. Tel.: +31 (0)40 247 2138, Fax +31 (0)40 2438595

E-mail address: b.j.e.blocken@tue.nl
} 
they can suffer from potentially incompatible similarity requirements. Like wind-tunnel testing, also CFD allows full control over the initial and boundary conditions. In addition, CFD provides whole-flow field data, i.e. data on the relevant parameters in all points of the computational domain. Unlike wind-tunnel testing, CFD does not suffer from potentially incompatible similarity requirements because simulations can be performed at full scale. In particular, CFD can allow insights in the flow and dispersion process that are very difficult to obtain otherwise. However, the accuracy and reliability of CFD are important concerns and solution verification and validation studies are imperative. The experimental data for validation in turn need to satisfy important quality criteria $[2,3]$.

In the past 50 years, CFD has increasingly been developed and applied as an assessment tool in wind engineering [5]. This is demonstrated by both general review papers (e.g. [5-13]) and review papers on topics of particular interest such as dispersion of pollutants (e.g. [14-18]). In two recent contributions, Tominaga and Stathopoulos [16] and Di Sabatino et al. [17] address the possibilities and limitations of Reynolds-Averaged Navier-Stokes (RANS) simulations versus Large Eddy Simulation. Tominaga and Stathopoulos [16] mention three key physical features of near-field pollutant dispersion, all of which are difficult to capture with RANS simulations: three-dimensionality of the flow, unsteadiness of the large-scale flow structures and anisotropy of turbulent scalar fluxes. LES on the other hand is capable of capturing all these features, on the condition that numerical and physical modelling errors can be limited. Indeed, care for accuracy and reliability is maybe even more important in LES than in RANS because, as stated by Hanna [19] “... as the model formulation increases in complexity, the likelihood of degrading the model's performance due to input data and model parameter uncertainty increases as well." In addition, a well-known problem of LES simulations is their high computational cost, which is easily one order of magnitude larger than for RANS [16]. This drawback becomes even more pronounced for practical applications, where generally simulations need to be performed for at least 12 wind directions [20]. The complexity of the model formulation of LES and its high computational cost are probably the main reasons why in many cases and especially in practical applications, steady RANS is still being used to assess near-field pollutant dispersion [18].

In spite of these limitations, LES can be applied as a research tool, to provide more insight into the dispersion process, by analyzing convective and turbulent mass fluxes, and to evaluate common turbulent transport models used with the RANS approach, such as the standard gradient-diffusion hypothesis (SGDH) (see e.g. [21]). Such an analysis, for an actual urban area, is the subject of the present paper.

In turbulent flows, molecular diffusion of a pollutant gas is generally negligible and pollutant dispersion can be seen as the combination of convective and turbulent mass transport, corresponding to the transport by the mean flow and by the turbulent fluctuations, respectively. This decomposition is actually the basic principle of the RANS turbulence modeling approach. The convective mass flux is given by:

$Q_{c, i}=U_{i} C$

where $U_{i}=\left\langle u_{i}\right\rangle$ is the time mean velocity in direction $i$ and $C=\langle c\rangle$ is the time mean concentration. The turbulent mass flux is defined as:

$Q_{t, i}=<u_{i}^{\prime} c^{\prime}>$

where the angle brackets denote time averaging and $u_{i}^{\prime}$ and $c^{\prime}$ are the velocity and concentration fluctuations, respectively. In RANS models, $\mathrm{Q}_{\mathrm{c}, \mathrm{i}}$ is computed based on the mean variables while the turbulent mass flux needs to be modeled because the turbulent fluctuations of velocity and concentration are not explicitly resolved. The turbulent mass flux is generally assumed to be proportional and opposite to the gradient of the mean concentration, with the so-called gradient-diffusion hypothesis or first-order closure:

$Q_{t, i}=-D_{t} \frac{\partial C}{\partial x_{i}}$

with $D_{t}$ being the turbulent mass diffusivity. Often, $D_{t}$ is assumed to be a scalar, while actually being a tensor, and Eq. (3) then represents that "standard" gradient-diffusion hypothesis (SGDH).

A large majority of the CFD studies of pollutant dispersion with the RANS turbulence modeling approach use the SGDH to compute the turbulent mass flux, mainly because of the simplicity of this model (e.g. [22-26]). RANS simulations of pollutant dispersion with other mass-flux models are rather rare in the literature (e.g. [2729]). The SGDH has two main disadvantages: (i) the fact that $D_{t}$ is often not a scalar but a tensor and (ii) the fact that it is strongly dependent on the turbulent Schmidt number $\left(S c_{t}=v_{t} / D_{t}\right)$ input value that allows computation 
of $D_{t}$ based on the turbulent viscosity $v_{t}[30]$. Generally, this value is taken to be constant in space and time, while often it is a function of the type of flow field and varies in space and time. Furthermore, in some cases like, for example, dispersion from a rooftop vent on a cubical building and, more generally, for shear-dominated flows, it appears that the SGDH is not always valid: in the streamwise direction, turbulent mass transport can act from low to high levels of the mean concentration. Further investigation of the underlying physical mechanism as performed in [32] showed the importance of the large-scale vortical structures present in the shear layers developing from the roof and sides of a cubical building with its windward facade perpendicular to the approach flow. These structures create peaks of both velocity and concentration fluctuations. The fluctuations of the streamwise velocity and concentration are most of the time of opposite sign, which explains why the covariance (i.e. $\left\langle u^{\prime} c^{\prime}\right\rangle$, the streamwise component of the turbulent mass flux) is negative, hence of the same sign as the mean concentration derivative in this direction.

The present study aims at providing more insight into the dispersion process, by analyzing convective and turbulent mass fluxes, and to evaluate the validity of the SGDH for near-field dispersion in the actual urban area of part of downtown Montreal, Canada. The density of the surrounding buildings is high, which makes the flow and concentration field particularly complex and challenging to predict. The LES simulations reproduce the wind-tunnel experiments by Stathopoulos et al. [33]. In an earlier study [34], these LES simulations were used to predict mean surface-concentration values. In contrast to the previous study, the present study focuses mainly on the spatial plume structure and dispersion process. For this purpose, it will be shown that in the main area of interest, the SGS mass flux is about two orders of magnitude smaller than the total turbulent mass flux . This indicates that LES provides an accurate estimation of the turbulent mass flux and can therefore be used to provide insight in the dispersion process and the validity of the SGDH.

\section{Numerical model}

\subsection{Computational domains, grids and boundary conditions}

Two wind-tunnel experiments of pollutant dispersion in downtown Montreal performed by Stathopoulos et al. [33] at scale 1:200 are reproduced with ANSYS/Fluent 6.3. $\mathrm{SF}_{6}$ is used as a tracer gas and is released from a stack on the roof of a three-story building (named 'BE building') in the city center (Fig. 1). The first case (case $\mathrm{SW}$ ) is for southwest wind direction, a stack height $h_{s}=1 \mathrm{~m}$ (full-scale dimensions) and a velocity ratio $M=$ $W_{e} / U_{H}=5$, with $W_{e}$ the stack exhaust velocity and $U_{H}$ the mean approach-flow wind velocity at building height $(H=13.6 \mathrm{~m})$. For this wind direction, the BE building is located immediately downstream of the Faubourg building (Fig. 1b). The second case (case W) is for westerly wind direction, $h_{s}=3 \mathrm{~m}$ and $M=3$. In this case, the emitting building is located in the far wake of several high-rise buildings (Fig. 1c). Note that the stack location is different for these cases.

The computational domains and grids are identical to those used for the simulations in [34], where they were named "SW-m" and "W-m". The domain dimensions are based on the COST Action 732 and AIJ guidelines [35,36]: $5 \times 2.125 \times 1.65 \mathrm{~m}^{3}(73.5 \mathrm{H} \times 31.2 \mathrm{H} \times 24.3 \mathrm{H})$ for case $\mathrm{SW}$ and $5.75 \times 2.3 \times 1.65 \mathrm{~m}^{3}$ $(84.5 \mathrm{H} \times 33.8 \mathrm{H} \times 24.3 \mathrm{H})$ for case $\mathrm{W}$ at reduced scale $1: 200$, and the inlet and outlet planes are perpendicular to the flow direction $(x)$ in both cases. The spanwise and vertical coordinates correspond to $y$ and $z$, respectively.

The high-resolution computational grids are shown in Figures 2 and 3. They have been created with the surface-grid extrusion technique [37]. The resolution was determined using a grid-sensitivity analysis. The grids for the cases SW and W are composed of 4,791,744 and 5,257,343 hexahedral cells, respectively, arranged in a horizontally-unstructured and vertically-structured way. The dimension of the cells ranges from a few centimeters around the source (full-scale dimensions) to several meters at the external boundaries of the domain in order to keep a reasonable total number of cells. This inevitably leads to cells with a high aspect ratio which are not optimal for LES but which can hardly be avoided in practice. A previous LES study of wind flow around an isolated building with aspect ratio 1:1:2 [38] has shown that 20 cells per building side are sufficient to ensure a well-resolved LES in the sense that $80 \%$ of the total turbulent kinetic energy is resolved. Considering the highresolution used here to discretize the emitting building (e.g. $130 \times 96 \times 49$ for case SW), it can be inferred that the present simulation constitutes a well-resolved LES in the region of interest around the emitting building.

At the inlet of the domain, the profiles of mean wind speed $U$, turbulent kinetic energy $k$ and turbulence dissipation rate $\varepsilon$ are imposed, based on the wind-tunnel measurements. For both wind directions the mean velocity profile is given by the power law:

$$
\frac{U(z)}{U_{r e f}}=\left(\frac{z}{z_{r e f}}\right)^{\alpha}
$$


where $\alpha=0.3$. The turbulent kinetic energy is given by:

$k(z)=\left(I_{u} U\right)^{2}$,

with $I_{u}$ the streamwise turbulence intensity $\left(I_{u}=\sigma_{u} / U\right.$, with $\sigma_{u}$ the standard deviation of $u$ ) which is $35 \%$ at ground level and $5 \%$ at $0.6 \mathrm{~m}$ height in the wind tunnel. Note that the $k$-profile has been deduced following the assumption $\sigma_{u}{ }^{2}=\sigma_{v}{ }^{2}+\sigma_{w}{ }^{2}[36,39]$. The $\varepsilon$-profile is based on the assumption of equilibrium between production and dissipation of turbulent kinetic energy in the incoming flow:

$\varepsilon(z)=\frac{u_{A B L}^{* 3}}{\kappa\left(z+z_{0}\right)}$,

with $u^{*}=1.01 \mathrm{~m} \mathrm{~s}^{-1}$ the friction velocity, $\kappa=0.41$ the von Karman constant and $z_{0}=0.0033 \mathrm{~m}$ (model scale) the aerodynamic roughness length. The prescribed profiles allow generating the time-dependent velocity profile at the inlet of the domain using the vortex method [40] with 190 vortices. Two-dimensional vortices whose individual size and intensity depend on the local value of $k$ and $\varepsilon$ are created and transported randomly in the inlet plane and generate in this way perturbations on the lateral and vertical velocity components. Perturbations imposed on the mean streamwise velocity are deduced from the perturbations induced in the inlet plane [40]. However, it should be noted that this method generally does not produce appropriate integral length scales and is generally not divergence-free. For more information on this matter and improved methods of velocity inlet boundary conditions, the reader is referred to [41-44].

The resulting vertical profiles of non-dimensional mean streamwise velocity $U / U_{H}$ and streamwise turbulence intensity $I_{u}$ obtained with the vortex method are compared to those measured in the wind tunnel in Figure 4. Note that the numerical profiles are averaged in the lateral direction. While the agreement is good for $U / U_{H}$, one can notice the under-estimation of $I_{u}$ by the CFD model by about $36 \%$ at the BE building height. This is attributed to the vortex method, which generates too low velocity fluctuations in the streamwise direction, and to the assumptions stated earlier for the computation of the turbulent kinetic energy and turbulence dissipation rate at the inlet. However, the under-estimation of $I_{u}$ at the inlet is assumed to have a relatively low influence on the plume dispersion since the turbulence at the location of the emitting building is mainly generated by the presence of the surrounding buildings. Note that experimental data of $I_{v}$ and $I_{w}$ were not available.

The exhaust face of the stack is defined as a velocity inlet. The hydraulic diameter $(0.002 \mathrm{~m}$ at model scale) and an assumed value of turbulence intensity of $10 \%$ are prescribed in order to generate fluctuations on the mean velocity profile (uniform on the exhaust face) with the vortex method [40]. The top and lateral boundaries of the domain are defined as symmetry boundaries. At the outlet plane, zero static pressure is imposed. The ground and building surfaces are defined as walls and each wall-adjacent cell's centroid is assumed to fall either in the linear sub-layer, in the buffer layer or in the logarithmic region of the boundary layer, depending on its distance from the wall [45]. Note that the roughness of the ground is not taken into account in the wall treatment imposed at this boundary but the empty length upstream of the buildings is sufficiently short to limit the degradation of the inflow profiles imposed at the inlet of the domain [46,47]. In addition, the presence of the upstream buildings and the related building-generated turbulence is expected to significantly reduce the influence of any unintended streamwise gradients [47] in the empty upstream length of the domain.

\subsection{Turbulence and dispersion modeling}

With LES, the flow equations are filtered so that the distinction is made between the scales of motion which are smaller than the filter width (equal to the grid size in this case) and those that are larger. Only the largest scales of motion are explicitly resolved. LES is used here with the dynamic Smagorinsky subgrid-scale (SGS) model [48-50]. The Smagorinsky coefficient is computed at each time step based on the smallest resolved scales.

Dispersion of the pollutant gas is treated with the Eulerian approach: the $\mathrm{SF}_{6}$ concentration is considered as a passive scalar $(c)$ transported by an advection-diffusion equation. The results are expressed in nondimensional form with the concentration coefficient $K$ :

$$
K=\frac{\chi H^{2} U_{H}}{Q_{e}}
$$


where $\chi$ is the mean $\mathrm{SF}_{6}$ mass fraction and $Q_{e}$ is the exhaust rate $\left[\mathrm{m}^{3} \mathrm{~s}^{-1}\right]$. Note that, following the definition used in the report of the experiments $K$ is expressed as a function of $\chi$, which is directly linked to the concentration $c$ $\left[\mathrm{kg} \mathrm{m}^{-3}\right]$. Once filtered, the dispersion equation contains the so-called SGS mass flux $\overrightarrow{q_{s g s}}$, representing the effects of the smallest scales of motion on the resolved concentration field. It is computed based on the gradient of the resolved concentration:

$q_{s g s, i} \equiv \overline{u_{i} c}-\bar{u}_{i} \bar{c}=-D_{s g s} \frac{\partial \bar{c}}{\partial x_{i}}$

where the overbar represents the filtering operator and $D_{s g s}$ is the SGS mass diffusivity computed via the SGS viscosity $v_{s g s}$ and the SGS Schmidt number $S c_{s g s}=v_{s g s} / D_{s g s}$, which is here computed at each time step using a test filter, with a similar procedure as the Smagorinsky coefficient $C_{s}[50,51]$.

To analyze the dispersion process, the time mean mass transport is decomposed into the transport by the time mean flow field and by the turbulent fluctuations. The former corresponds to the (time mean) convective mass flux $\overrightarrow{Q_{c}}$ and the latter to the turbulent mass flux $\overrightarrow{Q_{t}}$. In the LES framework, these fluxes are defined as follows:

$Q_{c, i}=<\bar{u}_{i}>\times<\bar{c}>$

$Q_{t, i}=<\bar{u}_{i} \bar{c}^{\prime}>+<q_{s g s, i}>$

where the angle brackets denote the time averaging operator, the overbar indicates a filtered variable and the apostrophe denotes the fluctuation of a given variable in such a way that $c(t)=\langle c\rangle+c^{\prime}(t)$. Note that the time mean value of a variable is symbolized by a capital letter: $\langle c\rangle=C$. By extension, $\overrightarrow{Q_{s g s}}$ corresponds to the vector of components $Q_{s g s, i}=\left\langle q_{s g s, i}\right\rangle$. In the next section the computed fluxes are presented in non-dimensional form related to $Q_{0}$, the reference flux $\left[\mathrm{kg} \mathrm{m}^{-2} \mathrm{~s}^{-1}\right]$, which is defined by:

$Q_{0}=\frac{Q_{e} \rho_{S F 6}}{H^{2}}$

where $\rho_{S F 6}$ is the density of $\mathrm{SF}_{6}$.

\subsection{Numerical procedure}

The momentum equation is discretized with a bounded central-differencing scheme and a second-order upwind scheme is used for the energy and $\mathrm{SF}_{6}$ concentration equations. Pressure interpolation is second order. Time integration is second order implicit. The non-iterative fractional step method [53] is used for time advancement. The time step is set to $\Delta t=5 \times 10^{-4} \mathrm{~s}$ in both cases, leading to a Courant number below 1 in the majority of the cells. The corresponding non-dimensional time step is $\Delta t^{*}=\Delta t \times U_{H} / H=0.048$. The results presented hereafter have been averaged over a period of $6 \mathrm{~s}(12,000$ time steps $)$, corresponding to 15 flow-through times $\left(T_{f t}=\right.$ $L_{x} / U_{r e f}$, where $L_{x}$ is the length of the domain and $U_{r e f}$ is the mean streamwise velocity at $0.6 \mathrm{~m}$ height) for case SW.

\section{Results: southwest wind direction (case SW)}

\subsection{Mean concentration field}

Figure 5a shows a top view of the BE building and the Faubourg building with indication of the stack location (SL3), the 15 wind-tunnel measurement positions (13 on the roof of the BE building and 2 at the top of the leeward facade of the Faubourg building) and the measured values (100K). Figure 5b compares computed and measured values at the 15 measurement positions, showing a good agreement, with computed values within a factor of 3 from the measurements. Overall, the LES simulation underestimates the concentration values. This can be attributed to the lower approach-flow turbulence intensity (Fig. 4b). A larger approach-flow turbulence intensity could have resulted in stronger mixing in the near-wake region downwind of the Faubourg facade. This in turn could have resulted in higher pollution concentrations further downstream of this facade. Figure $6 \mathrm{~b}$ shows the contours of $K$ in the vertical plane $y=y_{\text {stack }}$ aligned with the wind direction and containing the stack, and Figure $6 \mathrm{c}$ shows the contours of $\mathrm{K}$ in the horizontal plane $z / H=1.47$, corresponding to $20 \mathrm{~m}$ height in fullscale dimensions. The plume is deviated towards the leeward facade of the upstream Faubourg building, against 
the approach-flow wind direction. In the horizontal plane, one can notice the asymmetry of the plume shape with respect to the plane $y=y_{\text {stack }}$. This feature is attributed to the irregular shape of the Faubourg building. Further analysis of the plume features can be performed by the observation of the mass fluxes.

\subsection{Mass fluxes}

In order to evaluate the relative contribution of mass transport modeling $\left(\overrightarrow{Q_{s g s}}\right)$ with respect to what is resolved by the LES model $\left(\left\langle\bar{u}_{i} \bar{c}^{>}\right\rangle\right)$, the ratio of the SGS mass flux magnitude to the total turbulent mass flux magnitude is depicted in Figure 7. Note that the SGS contribution is evaluated here with the model in use (Eq. 2), whose accuracy is not proven. However, even if not perfectly accurate, this model can reasonably be assumed to provide the correct order of magnitude for the SGS mass flux. In the region above the emitting building, the magnitude of $\overrightarrow{Q_{s g s}}$ is at least two orders of magnitude smaller than $\overrightarrow{Q_{t}}$. This is attributed to the high grid resolution that has been used to discretize the BE building and to discretize the stacks on its roof (the four different stack locations used in the experiment were included in each computational grid). The contribution of the subgrid scales becomes more important around the Faubourg building and reaches levels above $10 \%$. The reason is twofold: first, larger cells are used in the computational grid around this neighboring building and, second, relatively large gradients of concentration are present at these locations (see Eq. 2). However, it should be emphasized that since the velocity and concentration fluctuations are weaker at this location, the magnitude of the total turbulent flux is low and the relatively large contribution of the subgrid scales does not significantly affect the dispersion of the pollutant. Note that the dynamic treatment of $S c_{s g s}$ avoids the input of any parameter to compute the SGS mass flux. Otherwise, $S c_{s g s}$ is a user input. It seems that no consensus exists in the literature on any particular value, considering the various values that can be found, e.g. 0.5 in [54], 0.6 in [55], 0.72 in [56] or 0.9 in [57].

The contours of non-dimensional convective mass flux in the streamwise direction $\left(Q_{c, x} / Q_{0}\right)$ are depicted in Figures $8 \mathrm{a}$,b. In the plane $y=y_{\text {stack }}$ (Fig. 8a), the blue zone corresponds to the mean backflow occurring in the wake of the Faubourg building. The negative values of the mean velocity observed in this region are partly (together with the turbulence effects, see later) responsible for the backward transport of the pollutant and the resulting $K$-contours observed earlier. In the upper region (around the roof level of the Faubourg building) and farther downstream, the mean streamwise velocity is positive and carries the pollutant gas downstream $\left(Q_{c, x}>\right.$ $0)$. At first, the flow and dispersion patterns in the wake of the Faubourg building seem rather similar to the case of a pollutant source placed in the wake of a generic simple building [58,59]. However, the observation of the contours in the horizontal plane $z / H=1.47$ (Fig. 8b) reveals that small irregularities in the Faubourg building shape are responsible for significantly different flow characteristics. Instead of being negative in the entire region behind the building (i.e. what would happen for a rectangular-shaped building with wind flow perpendicular to the facade), $Q_{c, x}$ is positive in the zone colored in red (dark gray) for $y>y_{\text {stack}}$, and a totally different plume shape could be expected if the source was located in this region. The asymmetry of the wake can also be observed in the contours of $Q_{c, y} / Q_{0}$ (Fig. 8d); the stack is located in a region of negative convective flux in the lateral direction, which partly explains the slight deviation towards the negative y-direction at the level of the stack, as observed in Figure 6c. The relatively high vertical velocity at the exhaust can be observed in Figure 8c: the vertical convective flux is intense and reaches high values up to the roof of the Faubourg building. Farther downstream, reattachment of the flow occurs, leading on average to negative mean vertical velocity and $Q_{c, z}<0$.

The contours of the turbulent mass flux components normalized by $Q_{0}$ are depicted in Figure 9 . In the streamwise direction (Figs. 9a,b), the sign of the flux is opposite to that of $\partial C / \partial x$ in the vicinity of the stack, with blue (resp. red) zones corresponding to “+” (resp. “-”) sign. Hence, the standard gradient-diffusion (SGD) hypothesis generally used with RANS models is verified in this zone. As stated earlier, it is shown here that the deviation of the plume towards the leeward facade of the Faubourg building is not only due to the mean flow but also to the turbulent fluctuations. At the Faubourg building's roof level, $Q_{t, x}$ is opposite to $Q_{c, x}$ and is relatively less intense (Fig. 9a). This large region colored in blue and light blue (light gray) is partly characterized by a decrease of mean concentration in the zone marked "CG" (i.e. Counter-Gradient) in the figure: here the turbulent mass transport obeys a counter-gradient mechanism, presumably due to the vortical structures generated at the front corner of the Faubourg building that are transported downstream in this area [32]. However, due to the lower location of the pollutant source in this case, this phenomenon does not play a major role on the dispersion, contrary to the case where the emitting building would directly face the ABL flow without upstream obstruction [21]. Another CG zone of turbulent mass transport is identified in the horizontal plane $z / H=1.47$ (Fig. 9b): the blue zone starting from the northern corner of the Faubourg building where $Q_{c, x}$ and $\partial C / \partial x$ are both negative. As described in [32] for a cubical building, vortical structures are present in the shear layers developing on the sides of the building and are responsible for this mechanism of turbulent mass transport. In the vertical and lateral directions (Figs. 9c,d), the SGD hypothesis is generally verified: $Q_{t, z}$ and $Q_{t, y}$ 
are directed from the high to low levels of mean concentration. In these directions, the convective and turbulent mass transport mechanisms act with similar intensity.

\section{Results: west wind direction (case $W$ )}

\subsection{Mean concentration field}

Figure 10a shows the stack location (SL1), the 14 wind-tunnel measurement positions on the roof of the BE building and the measured values $(100 \mathrm{~K})$. Figure $10 \mathrm{~b}$ compares computed and measured values at the 14 measurement positions. For 8 positions, the agreement is good (within a factor 4 ), however deviations are very large for 6 positions (note that 2 symbols are overlapping). These positions and values are encircled in the figures. The large underestimations by the LES simulation are mainly attributed to the deviation of the plume shape, as explained below. The isosurface $K=1$ and the contours of $K$ in the planes $y=y_{\text {stack }}$ and $z / H=1.47$ for case $\mathrm{W}$ are shown in Figure 11. Note that the figures are flipped compared to case SW to allow visualizing the plume: the wind direction is from right to left. The buildings that can be seen upstream of the BE building in Figures $11 \mathrm{~b}, \mathrm{c}$ are relatively far from it, outside of the plane $y=y_{\text {stack }}$ (see also Fig. 3 ) and do not significantly disturb the plume trajectory. As a consequence, the pollutant gas is mainly transported downstream by the wind flow. In Figure 11c, it can be seen that the plume centerline is not aligned with the flow direction. The plume is subjected to a deviation towards the positive y-direction, which was not observed in the wind-tunnel experiment and is therefore interpreted as the main reason for the relatively large discrepancies observed for this case between numerical and experimental values of concentration on the roof of the emitting building (Fig. 10b).

\subsection{Mass fluxes}

The contribution of the unresolved scales to the total turbulent mass flux in the area of interest is also minor in this case. In the two planes shown in Figure 12, the SGS mass flux is about two orders of magnitude smaller than the total turbulent mass flux. Higher contributions are observed around the Faubourg building without large impact on the plume dispersion.

Contrary to case SW, the pollutant source in case $\mathrm{W}$ is not located in the immediate vicinity of high-rise buildings and the plume is consequently less disturbed, as already shown in the previous section. No backflow is observed at the stack location and the streamwise component of the convective mass flux is therefore positive in this region (Figs. 13a,b). Note that a small region downstream of the Faubourg building is characterized by $Q_{c, x}$ $<0$ (see Fig. 13b) but the magnitude of the associated flux is low because only a small pollutant quantity reaches this zone. The vertical velocity is negative in the plane $y=y_{\text {stack }}$ (except around the stack exhaust), leading to $Q_{c, z}<0$ (Fig. 13c). This is due to the downflow created by the high-rise buildings present in the upstream region of the domain (see Fig. 3). As far as the lateral component of the convective flux is concerned, Figure $13 \mathrm{~d}$ shows that it is positive at the stack, which creates the plume deviation observed in the mean concentration contours. The positive lateral velocities at this location are due to the presence of the Faubourg building, which causes a change in the direction of the incoming wind flow. It should be noticed that the sign of $Q_{c, y}$ becomes opposite very close to the stack. Therefore, a small change in the stack location towards the zone colored in blue (light gray) in Figure $13 \mathrm{~d}$ would cause a very different plume behavior. This constitutes a possible explanation for the poor agreement between the $K$-values computed by LES and those measured in the wind tunnel.

In Figure 14a, the contours of the streamwise turbulent mass flux in the plane $y=y_{\text {stack }}$ are shown. It appears that while the mean concentration is decreasing from the stack exhaust towards the positive $\mathrm{x}$-direction, the streamwise component of the turbulent mass flux is negative. Turbulent mass transport is therefore following a CG mechanism in this direction and at this location, marked "CG" in the figure. However, when observing the field of $Q_{t, x} / Q_{0}$ in the plane $z / H=1.47$ (Fig. 14b), one can see that the link between the signs of the x-components of the turbulent mass flux and mean concentration gradient is not evident: $Q_{t, x}$ is changing sign along the plume centerline, from negative around the stack to positive farther downstream. Note that this change of sign is occurring at the level of the large structure present on the roof of the BE building. In [32], the role of the vortical structures on the process of turbulent mass transport was shown. Here, the turbulent eddies generated by the rooftop structure interact with those emanating from the front corner of the emitting building and possibly affect turbulent mass transport in the streamwise direction, resulting in the contours of $Q_{t, x}$ observed. Another important difference with the case of isolated buildings studied in the aforementioned reference is the orientation of the emitting building with respect to the incoming flow direction. It is known indeed that the structure of the flow around bluff bodies is strongly dependent on this parameter [60]. Further research on the influence of wind direction and of rooftop structures on the turbulent dispersion mechanism is needed to clarify this point. In the vertical direction (Fig. 14c), $Q_{t, z}>0$ in the region where $\partial C / \partial z<0$, and vice 
versa: the SGD hypothesis of turbulent mass transport is thus verified. The same conclusion holds for the lateral direction, as shown in Figure 14d.

\section{Discussion}

For case SW, the pollutant source is located in the wake recirculation zone of the high-rise Faubourg building. This wake has a particular asymmetric shape, different from that downstream of a simple rectangular building because of the irregular shape of the Faubourg building. The plume is deviated towards the leeward facade of the Faubourg building, not only due to the mean backflow, but also because of the turbulent fluctuations.

Nevertheless, convection appears to be the dominant mechanism of mass transport in the streamwise direction, emphasizing the need for accurate prediction of the mean flowfield by the CFD model. The use of LES is therefore recommended for this kind of study, taking into account its superior accuracy in comparison with RANS for the simulation of wind flow around bluff bodies.

The analysis of flow and dispersion around an isolated cubical building [32] has shown the crucial role played by the vortical structures in the turbulent dispersion process. These structures are responsible for the Counter-Gradient (CG) mechanism of turbulent dispersion occurring in the streamwise direction. This CG mechanism is not observed around the source for case SW, because of the absence of large-scale vortical structures at this location, in the wake of the Faubourg building. However, in the shear layers developing from the roof and sides of the Faubourg building, regions with a CG mechanism, i.e. where the turbulent mass flux is directed from the low to high levels of mean concentration, are present. Similar to the case of dispersion around an isolated building, this is attributed to the vortices generated at the windward edges of the Faubourg building. In the lateral and vertical directions, convective and turbulent mass fluxes are of similar intensity and the turbulent mass flux is directed from the high to low levels of mean concentration, acting like a diffusion process.

For case $\mathrm{W}$, the influence of the surrounding buildings on the dispersion process is less pronounced, as can be seen in the plume shape and mean concentration contours. However, the vertical convective flux is negative, suggesting a significant influence of the high-rise upstream buildings on the local flow pattern around the BE building, even though they are located relatively far away from the BE building. The stack lies in a critical zone of the flowfield where the lateral component of velocity - and of convective mass flux - is changing sign within a short distance. Thus, a small change in the stack location would result in a very different plume behavior, which constitutes a possible explanation for the large deviations between computed and measured concentration values on the roof of the BE building. The CG mechanism of turbulent mass transport in the streamwise direction can be observed but only within a limited region around the source, which contrasts with the case of dispersion around an isolated building. The location where $Q_{t, x}$ is changing sign coincides with the position of a rooftop structure on the emitting building, which suggests that these structures affect turbulent dispersion and should not be neglected in the CFD model. Similarly, the orientation of the building with respect to the incoming wind flow direction affects the turbulent flow patterns and constitutes a possible explanation to the complexity of the turbulent mass flux field in this case. In the vertical and lateral directions, turbulent mass transport acts as a diffusion mechanism - like for case SW, with the turbulent mass flux directed from the high to low levels of mean concentration.

For the two wind directions under study, the magnitude of the SGS mass flux appears to be at least two orders of magnitude smaller than that of the total turbulent mass flux in the region of interest, i.e. the region with high pollutant concentrations above the emitting building. This is an indication of appropriate grid resolution in this region. Larger contributions $(>10 \%)$ of the scales smaller than the grid size are observed around the surrounding buildings due to an increase of the cell size and a decrease of the velocity and concentration fluctuations at these locations. However, this is sufficiently far from the source to have a small effect on the plume dispersion. It should be noted that by analogy with RANS modeling of the turbulent mass flux, the SGS mass flux with LES is assumed proportional and opposite to the gradient of resolved concentration. Considering the low contribution of the SGS mass flux, the SGS Schmidt number - which was computed here with a dynamic procedure - will have low influence on dispersion.

\section{Conclusions}

Large-Eddy Simulation of near-field pollutant dispersion in the actual urban environment of part of downtown Montreal has been performed. The case under study involves a stack on the roof of a low-rise building in downtown Montreal, for two different wind directions (southwest and west). The focus has been on the convective and turbulent (including subgrid-scale) mass fluxes computed by LES. The latter allows evaluating the standard gradient-diffusion (SGD) hypothesis generally used with the steady RANS turbulence modeling approach for turbulent mass transport. Also, an attempt has been made to link the results obtained here to those of earlier studies of dispersion around isolated buildings, in order to assess the relevance of generic studies for more complex practical applications. 
Because of the particular geometry of the building group, the wind flow and dispersion patterns in the modeled part of downtown Montreal are complex and difficult to predict, even qualitatively. In this sense, the present results have shown differences when compared to the simpler case of dispersion around an isolated building. For example the structure of the wake of the irregular-shaped Faubourg building for case SW was significantly different from that of a rectangular building.

However, some important similarities with the case of the isolated building were also found, such as the occurrence of the CG mechanism of streamwise turbulent mass transport for both wind directions. When using RANS, the turbulent mass flux model should therefore be able to reproduce this mechanism - contrary to the SGD hypothesis. Another example of similarity between applied and generic cases is the relative importance of the turbulent and convective mass transport: in the same way as dispersion around an isolated building, convection is dominant in the streamwise direction whereas the two flux types act with similar intensity in the two other directions for both cases SW and W. The physical insight gained in the study of generic cases is also precious when analyzing the results of more complex and applied cases. It has, for example, been possible to explain the absence of the CG mechanism of the streamwise turbulent mass transport around the source for the case SW, based on the conclusions of an earlier study of dispersion around an isolated building. Furthermore, simple generic cases can generally be simulated on computational grids containing a reasonable number of cells Hence, the simulations are more economical to run and can be used to test the accuracy of the numerical model, which can subsequently be applied to more complex applied cases. In this way, the present study supports the relevance of the investigation of environmental processes on generic, simplified cases.

Reciprocally, this study shows that applied cases are useful to give indications on which parameters are relevant to be tested for simplified cases. For example, the influence of the rooftop structures and of the orientation of the emitting building was indicated by the analysis of dispersion under westerly wind direction. Further research should therefore focus on - among others - the influence of these parameters on near-field pollutant dispersion around buildings.

\section{References}

1. Brunekreef B, Holgate ST. Air pollution and health. The Lancet 2002;360:1233-42.

2. Schatzmann M, Rafailidis S, Pavageau M. Some remarks on the validation of small-scale dispersion models with field and laboratory data. J Wind Eng Ind Aerodyn 1997;67:885-93.

3. Schatzmann M, Leitl B. Issues with validation of urban flow and dispersion CFD models. J Wind Eng Ind Aerodyn 2011;99:169-86.

4. van Hooff T, Blocken B. Full-scale measurements of indoor environmental conditions and natural ventilation in a large semi-enclosed stadium: possibilities and limitations for CFD validation. J Wind Eng Ind Aerodyn 2012;104-106:330-341.

5. Blocken B. 50 years of Computational Wind Engineering: Past, present and future. J. Wind Eng. Ind. Aerodyn. 2014;129:69-102.

6. Murakami S. Comparison of various turbulence models applied to a bluff body. J. Wind Eng. Ind. Aerodyn. 1993;46-47:21-36.

7. Murakami S. Current status and future trends in computational wind engineering. J. Wind Eng. Ind. Aerodyn. 1997;67\&68:3-34.

8. Murakami S. Overview of turbulence models applied in CWE-1997. J. Wind Eng. Ind. Aerodyn. 1998;74-76:1-24.

9. Murakami S, Ooka R, Mochida A, Yoshida S, Kim S. CFD analysis of wind climate from human scale to urban scale. J. Wind Eng. Ind. Aerodyn. 1999;81:57-81.

10. Baker CJ. Wind engineering - Past, present and future. J. Wind Eng. Ind. Aerodyn. 2007;95(9-11):843870.

11. Blocken B, Stathopoulos T, Carmeliet J, Hensen JLM. Application of CFD in building performance simulation for the outdoor environment: an overview. J. Building Perform. Simul. 2011;4(2):157-184.

12. Moonen P, Defraeye T, Dorer V, Blocken B, Carmeliet J. Urban Physics: Effect of the micro-climate on comfort, health and energy demand. Front. Arch. Res. 2012;1(3):197-228.

13. Blocken B. Computational Fluid Dynamics for Urban Physics: Importance, scales, possibilities, limitations and ten tips and tricks towards accurate and reliable simulations. Build. Environ. In press.

14. Britter RE, Hanna SR. Flow and dispersion in urban areas. Annu. Rev. Fluid Mech. 2003;35:469-96.

15. Meroney RN. Wind tunnel and numerical simulation of pollution dispersion: a hybrid approach. Working paper, Croucher Advanced Study Institute on Wind Tunnel Modeling, Hong Kong University of Science and Technology, 6-10 December, 2004, 60 pp. 
16. Tominaga, Y., Stathopoulos, T. CFD simulation of near-field pollutant dispersion in the urban environment: A review of current modelling techniques. Atmos. Environ. 2013;79:716-730.

17. Di Sabatino S, Buccolieri R, Salizzoni P. Recent advancements in numerical modelling of flow and dispersion in urban areas: a short review. Int. J. Environ. Pollution 2013;52, 3-4:172-191.

18. Blocken B, Tominaga Y, Stathopoulos T. Editorial to virtual special issue: CFD simulation of microscale pollutant dispersion in the built environment. Build. Environ. 2013;64: 225-230.

19. Hanna, S.R., 1989. Plume dispersion and concentration fluctuations in the atmosphere. Encyclopedia of environmental control technology. In: Air Pollution Control, Vol. 2. Houston, TX: Gulf Publishing Company, 547-582.

20. Yoshie R, Mochida A, Tominaga Y, Kataoka H, Harimoto K, Nozu T, Shirasawa T. Cooperative project for CFD prediction of pedestrian wind environment in the Architectural Institute of Japan. J. Wind Eng. Ind. Aerodyn. 2007;95(9-11):1551-1578.

21. Gousseau P, Blocken B, van Heijst GJF. CFD simulation of pollutant dispersion around isolated buildings: On the role of convective and turbulent mass fluxes in the prediction accuracy. J. Hazard. Mat. 2011;194:422-34.

22. Riddle A, Carruthers D, Sharpe A, McHugh C, Stocker J. Comparisons between FLUENT and ADMS for atmospheric dispersion modelling. Atmos. Environ. 2004;38:1029-38.

23. Blocken B, Sathopoulos T, Saathoff P, Wang X. Numerical evaluation of pollutant dispersion in the built environment: Comparisons between models and experiments. J. Wind Eng. Ind. Aerodyn. 2008;96:1817-31.

24. Lateb M, Masson C, Stathopoulos T, Bédard C. Numerical simulation of pollutant dispersion around a building complex. Build. Environ. 2010;45:1788-98.

25. Chavez M, Hajra B, Stathopoulos T, Bahloul A. Near-field pollutant dispersion in the built environment by CFD and wind tunnel simulations. J. Wind Eng. Ind. Aerodyn. 2011;99:330-9.

26. Hang J, Li Y. Age of air and air exchange efficiency in high-rise urban areas and its link to pollutant dilution. Atmos. Environ. 2011;45:5572-85.

27. Wang BC, Yee E, Lien FS. Numerical study of dispersing pollutant clouds in a built-up environment. Int. J. Heat Fluid Flow 2009;30:3-19.

28. Rossi R, Iaccarino G. Numerical simulation of scalar dispersion downstream of a square obstacle using gradient-transport type models. Atmos. Environ. 2009;43:2518-31.

29. Izarra R. Second moment modelling for the numerical simulation of passive scalar dispersio of air pollutants in urban environments. PhD thesis, Fachbereich Maschinenbau der Universität Siegen 2009.

30. Tominaga Y, Stathopoulos T. Turbulent Schmidt numbers for CFD analysis with various types of flowfield. Atmos. Environ. 2007;41:8091-9.

31. Rossi R, Philips DA, Iaccarino G. A numerical study of scalar dispersion downstream of a wallmounted cube using direct simulations and algebraic flux models. Int. J. Heat Fluid Flow 2010;31:80519.

32. Gousseau P, Blocken B, van Heijst GJF. Large-Eddy Simulation of pollutant dispersion around a cubical building: Analysis of the turbulent mass transport mechanism by unsteady concentration and velocity statistics. Environ. Poll. 2012;167:47-57.

33. Stathopoulos T, Lazure L, Saathoff P, Gupta A. The effect of stack height, stack location and roof-top structures on air intake contamination - A laboratory and full-scale study. IRSST 2004, report R-392.

34. Gousseau P, Blocken B, Stathopoulos T, van Heijst GJF. CFD simulation of near-field pollutant dispersion on a high-resolution grid: a case study by LES and RANS for a building group in downtown Montreal. Atmos. Environ. 2011;45:428-38.

35. Franke J, Hellsten A, Schlünzen H, Carissimo B. Best practice guideline for the CFD simulation of flows in the urban environment. : COST Action 732, 2007.

36. Tominaga Y, Mochida A, Yoshie R, Kataoka H, Nozu T, Yoshikawa M et al. AIJ guidelines for practical applications of CFD to pedestrian wind environment around buildings. J. Wind Eng. Ind. Aerodyn. 2008;96:1749-61.

37. van Hooff T, Blocken B. Coupled urban wind flow and indoor natural ventilation modelling on a highresolution grid: A case study for the Amsterdam ArenA stadium. Environ. Modell. Softw. 2010;25:5165.

38. Gousseau P, Blocken B, van Heijst GJF. Quality assessment of Large-Eddy Simulation of wind flow around a high-rise building: validation and solution verification. Comput. Fluids 2013;79: 120-133.

39. Ramponi R, Blocken B. CFD simulation of cross-ventilation for a generic isolated building: Impact of computational parameters. Build. Environ. 2012;53:34-48.

40. Mathey F, Cokljat D, Bertoglio JP, Sergent E. Assessment of the vortex method for large eddy simulation inlet conditions. Progress in Computational Fluid Dynamics 2006;6:58-67. 
41. Sagaut P, Deck S, Terracol M. Multiscale and Multiresolution Approaches in Turbulence. Imperial College Press London. ISBN: 186094650X; 2006.

42. Tabor, G.R., Baba-Ahmadi, M.H.: Inlet conditions for large eddy simulation: a review. Comput. Fluids 2010;39(4):553-567.

43. Poletto R, Craft T, Revell A. A new divergence free synthetic eddy method for the reproduction of inlet flow conditions for LES. Flow, Turbulence and Combustion 2013;91(3):519-539.

44. Kim Y, Castro IP, Xie ZT. Divergence-free turbulence inflow conditions for large-eddy simulations with incompressible flow solvers. Comput. Fluids 2013;84:56-68.

45. Fluent Inc. Fluent 6.3 User's Guide. Lebanon, USA: Fluent Inc., 2006.

46. Blocken B, Carmeliet J, Stathopoulos T. CFD evaluation of wind speed conditions in passages between parallel buildings-effect of wall-function roughness modifications for the atmospheric boundary layer flow. J. Wind Eng. Ind. Aerodyn. 2007;95:941-62.

47. Blocken B, Stathopoulos T, Carmeliet J. CFD simulation of the atmospheric boundary layer: wall function problems. Atmos. Environ. 2007;41:238-52.

48. Smagorinsky J. General circulation experiments with the primitive equations. I. The basic experiment. Monthly Weather Review 1963;91:99-164.

49. Germano M, Piomelli U, Moin P, Cabot WH. A dynamic subgrid-scale eddy viscosity model. Phys. Fluids 1991;A 3:1760-5.

50. Lilly DK. A proposed modification of the Germano subgrid-scale closure method. Phys. Fluids 1992;A 4:633-5.

51. Moin P, Squires K, Cabot W, Lee S. A dynamic subgrid-scale model for compressible turbulence and scalar transport. Phys. Fluids 1991;A3-11:2746-57.

52. Porté-Agel F. A scale-dependent dynamic model for scalar transport in large-eddy simulations of the atmospheric boundary layer. Bound.-Layer Meteorol. 2004;112:81-105.

53. Kim J, Moin P. Application of a fractional step method to incompressible Navier-Stokes equations. J. Comput. Phys. 1985;59:308-23.

54. Tominaga Y, Stathopoulos T. CFD modeling of pollution dispersion in a street canyon: Comparison between LES and RANS. J. Wind Eng. Ind. Aerodyn. 2011;99:340-8.

55. Dejoan A, Santiago JL, Martilli A, Martin F, Pinelli A. Comparison between large-eddy simulation and Reynolds-averaged Navier-Stokes computations for the MUST field experiment. Part II: Effects of incident wind angle deviation on the mean flow and plume dispersion. Bound.-Layer Meteorol. 2010;135:133-50.

56. Cheng WC, Liu CH. Large-Eddy Simulation of flow and pollutant transports in and above twodimensional idealized street canyons. Bound.-Layer Meteorol. 2011;139:411-37.

57. Boppana V, Xie ZT, Castro I. Large-Eddy Simulation of dispersion from surface sources in arrays of obstacles. Bound.-Layer Meteorol. 2010;135:433-54.

58. Yoshie R, Jiang G, Shirasawa T, Chung J. CFD simulations of gas dispersion around high-rise building in non-isothermal boundary layer. J. Wind Eng. Ind. Aerodyn. 2011;99:279-88.

59. Huber AH, Snyder WH, Lawson Jr. RE. The effects of a squat building on short stack effluents - A wind tunnel study. U.S. Environmental Protection Agency 1980, report EPA-600/4-80-055.

60. Castro IP, Robins AG. The flow around a surface-mounted cube in uniform and turbulent streams. J. Fluid Mech. 1977;79:307-35. 


\section{FIGURES}
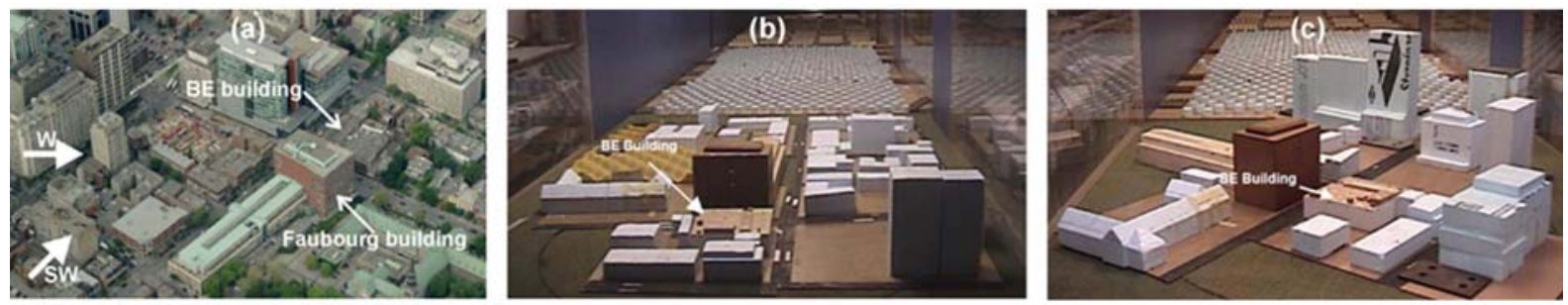

Figure 1. (a) View from south of the BE building and its surroundings in downtown Montreal and wind directions considered in the present study. (b,c) Wind-tunnel model for (b) case SW and (c) case W.
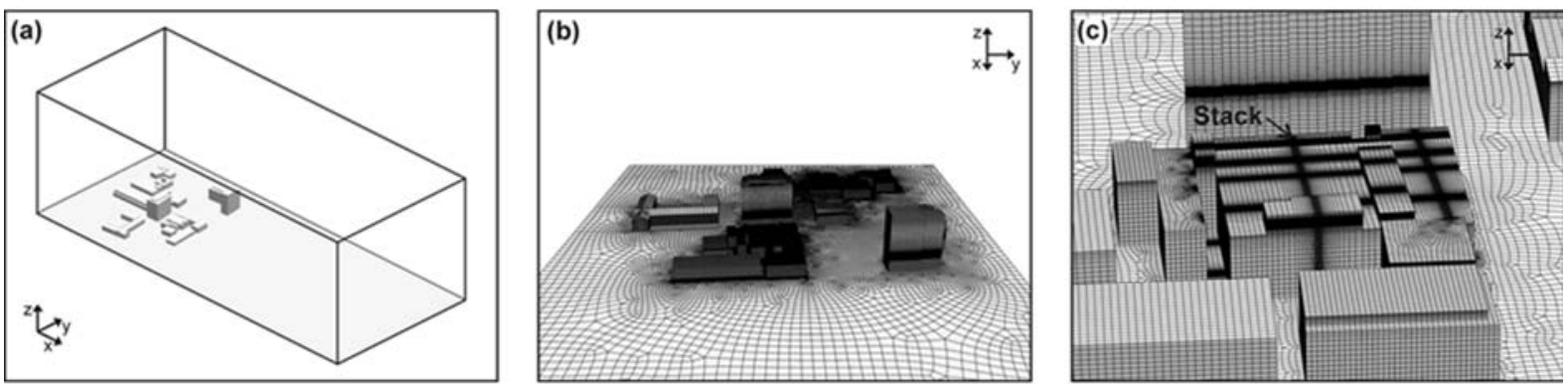

Figure 2. Case SW: (a) computational domain; (b) computational grid on the building and ground surfaces (total number of cells: 4,791,744); and (c) a close view of the grid on the BE building. The wind flow is in the $\mathrm{x}-$ direction (from back to front of the page).
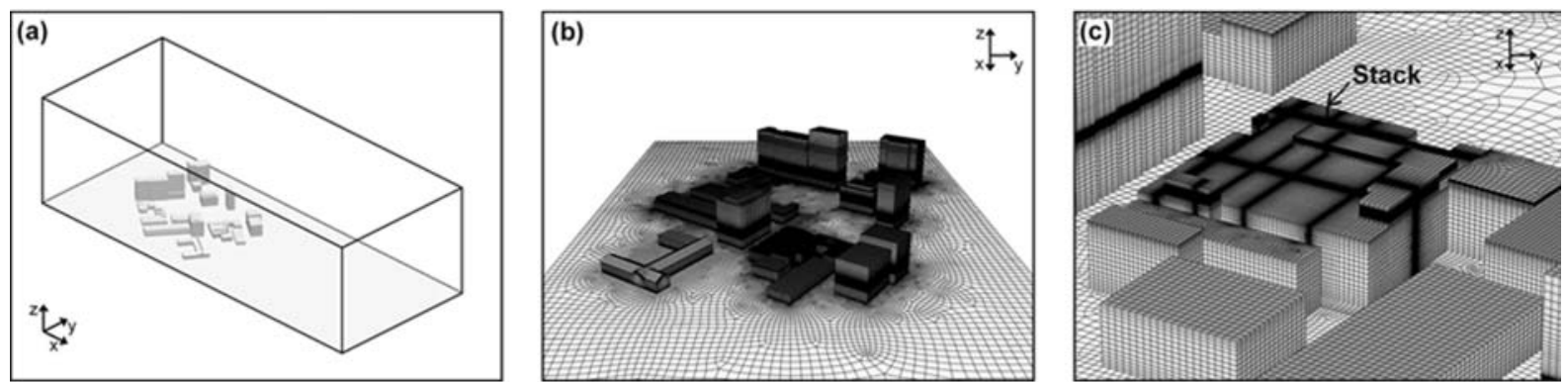

Figure 3. Case W: (a) computational domain; (b) computational grid on the building and ground surfaces (total number of cells: 5,257,343); and (c) a close view of the grid on the BE building. The wind flow is in the $\mathrm{x}-$ direction (from back to front of the page).

(a)

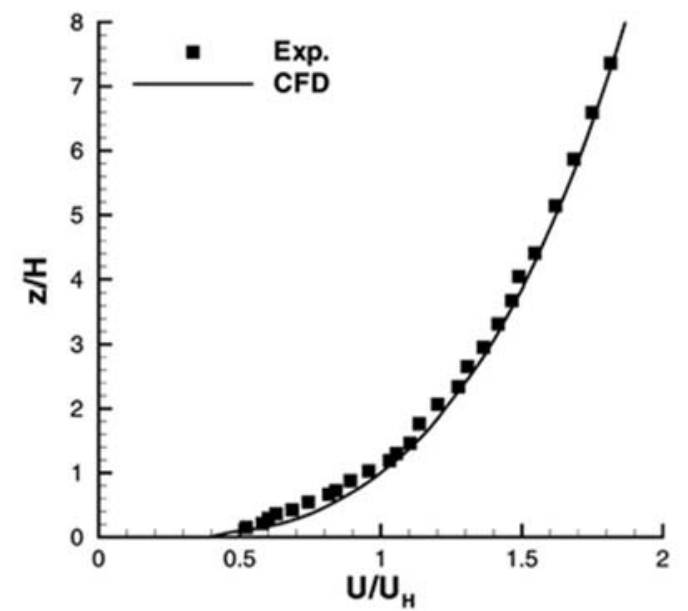

(b)

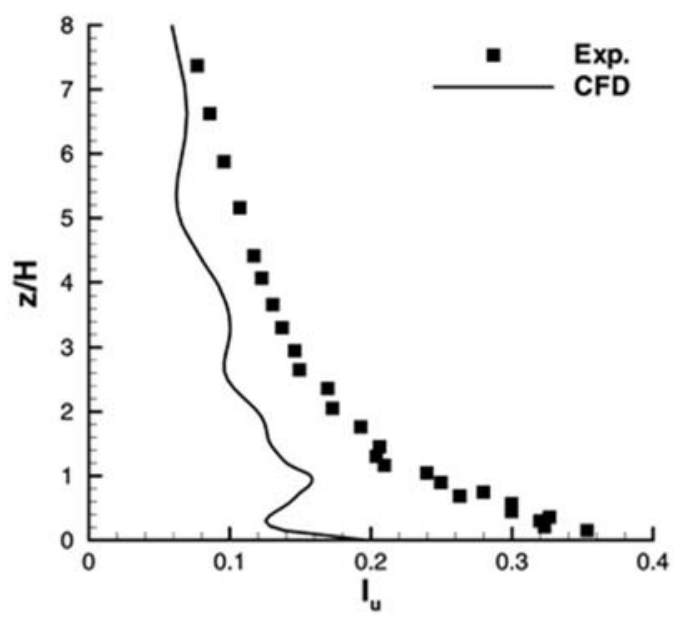

Figure 4. Experimental (symbols) and numerical profiles generated at the inlet of the computational domain (lines) of (a) non-dimensional mean streamwise velocity $\left(U / U_{H}\right)$ and (b) streamwise turbulence intensity $\left(I_{u}\right)$. 

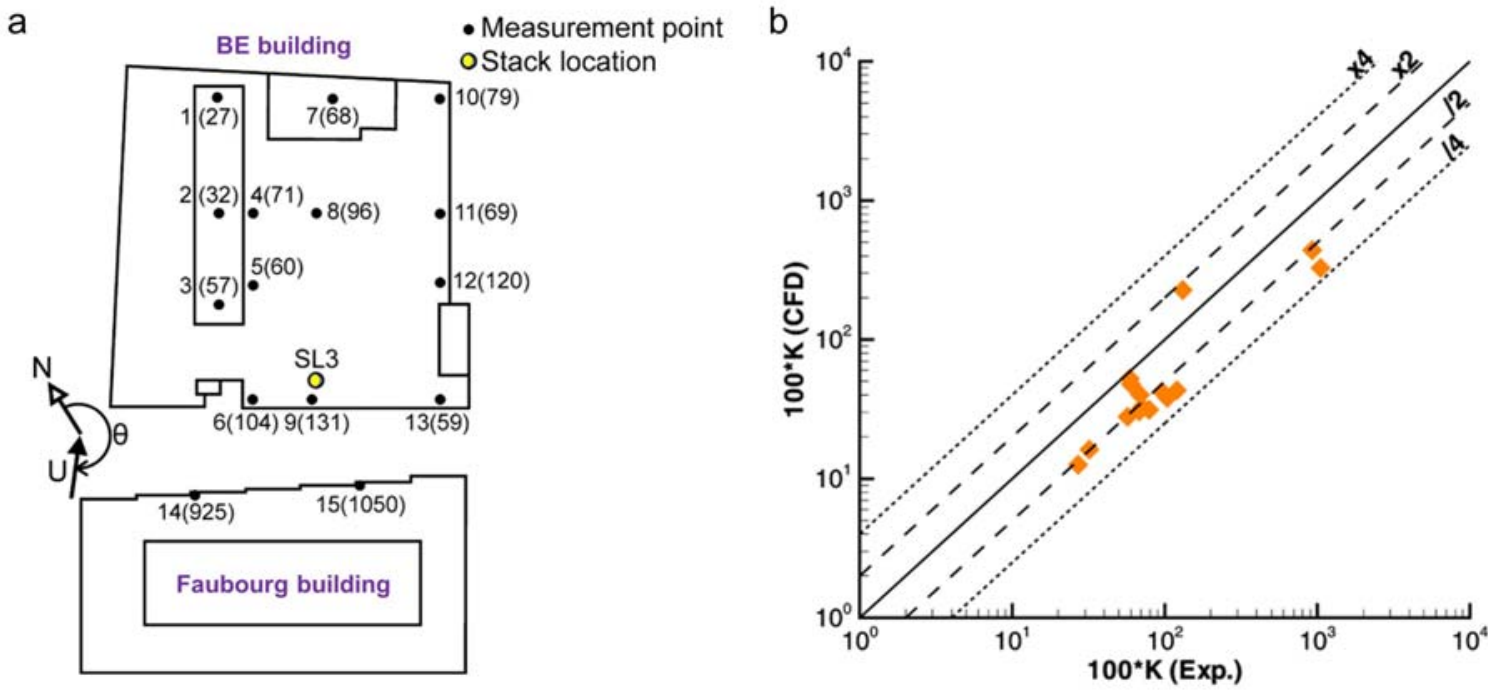

Figure 5. Case SW: (a) Top view of BE building and Faubourg building with indication of stack location (SL3), 15 measurement positions and measured values (100K). (b) Scatter plot of $100 \mathrm{~K}$ values comparing LES with experiments.
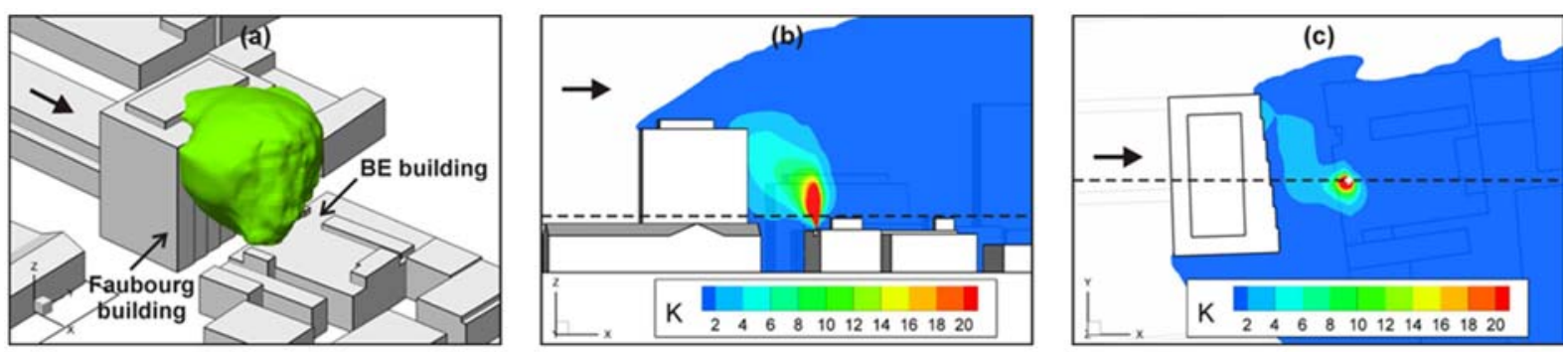

Figure 6. Case SW: (a) isosurface $K=1$ and (b,c) contours of the non-dimensional concentration coefficient $K$ in the planes (a) $y=y_{\text {stack }}$ and (b) $z / H=1.47$. The wind direction is indicated by the arrows. The dashed line in (b) indicates the position of the plane shown in (c), and vice versa.
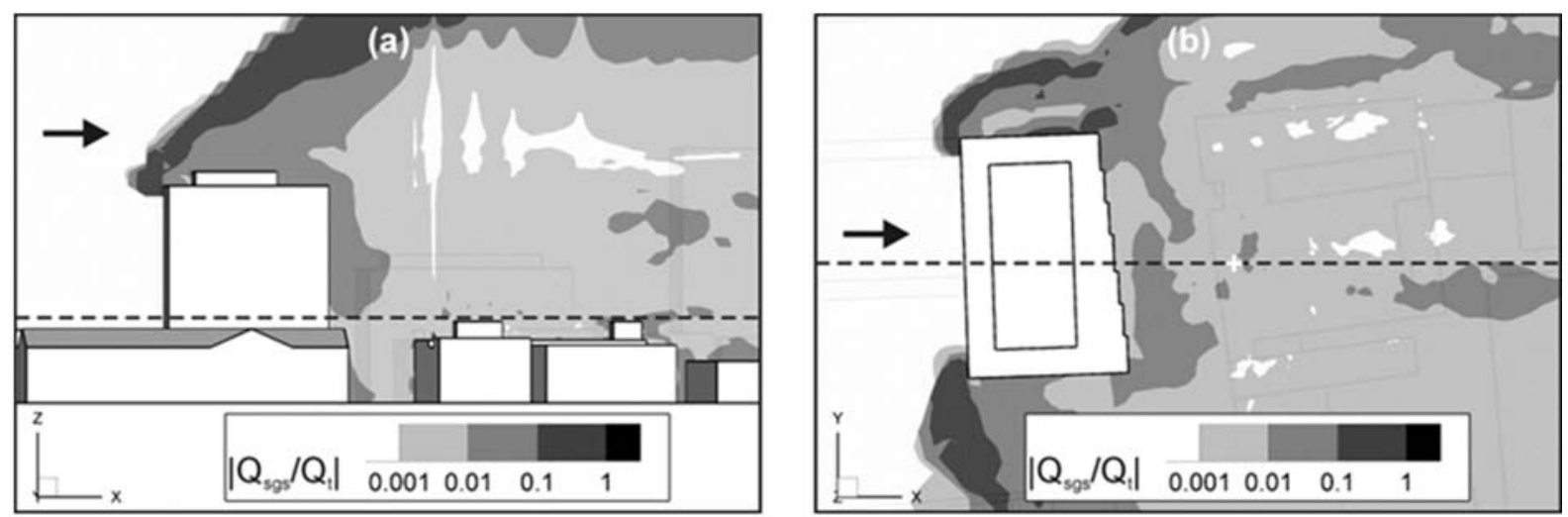

Figure 7. Case SW: relative contribution of the SGS mass flux to the total turbulent mass flux. Contours of $\left|Q_{s g s} / Q_{t}\right|$ in the planes (a) $y=y_{\text {stack }}$ and (b) $z / H=1.47$. 

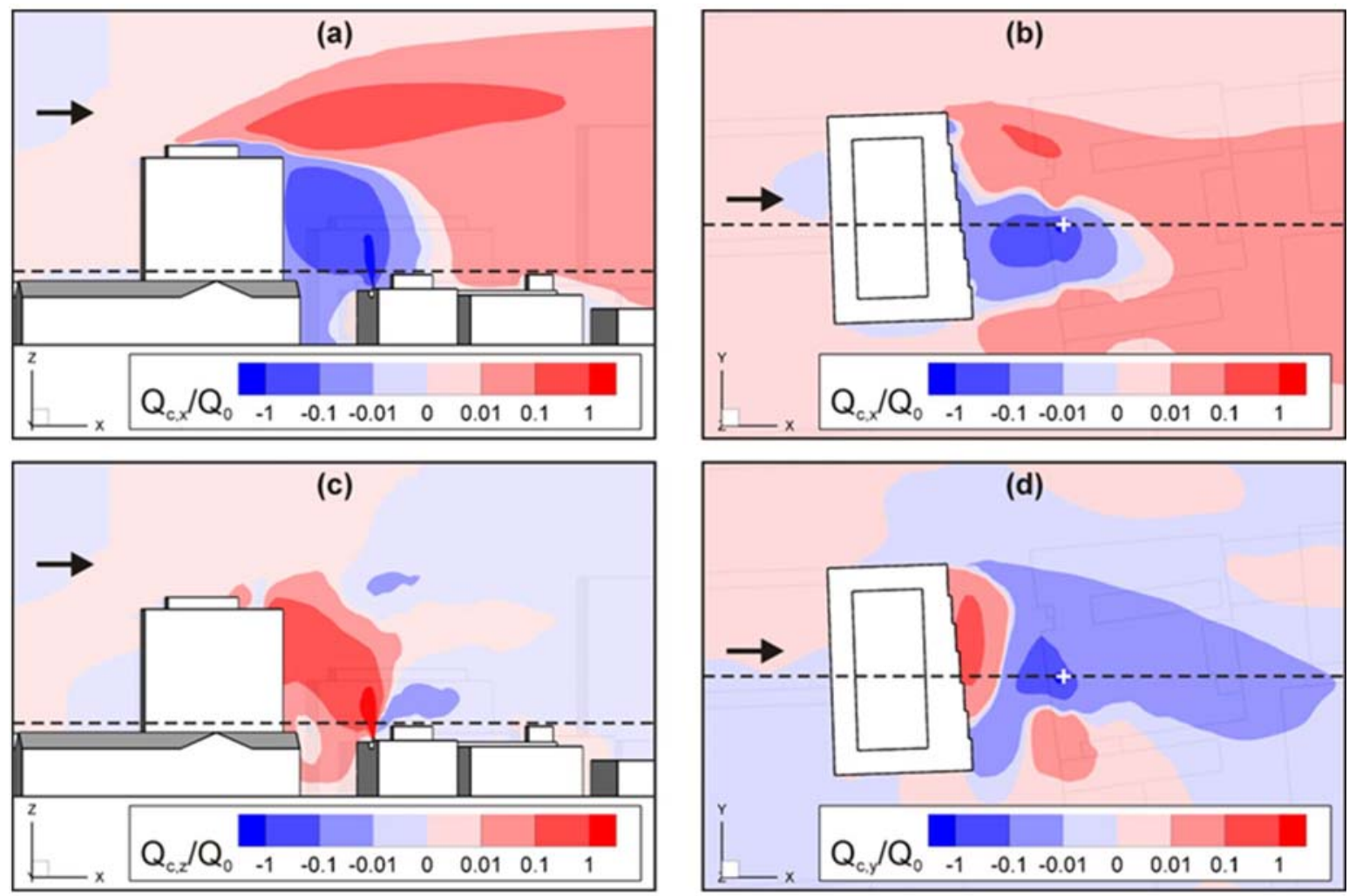

Figure 8. Case SW: contours of the (a,b) streamwise, (c) vertical and (d) lateral components of the nondimensional convective mass flux in the planes $(\mathrm{a}, \mathrm{c}) y=y_{\text {stack }}$ and $(\mathrm{b}, \mathrm{d}) z / H=1.47$.
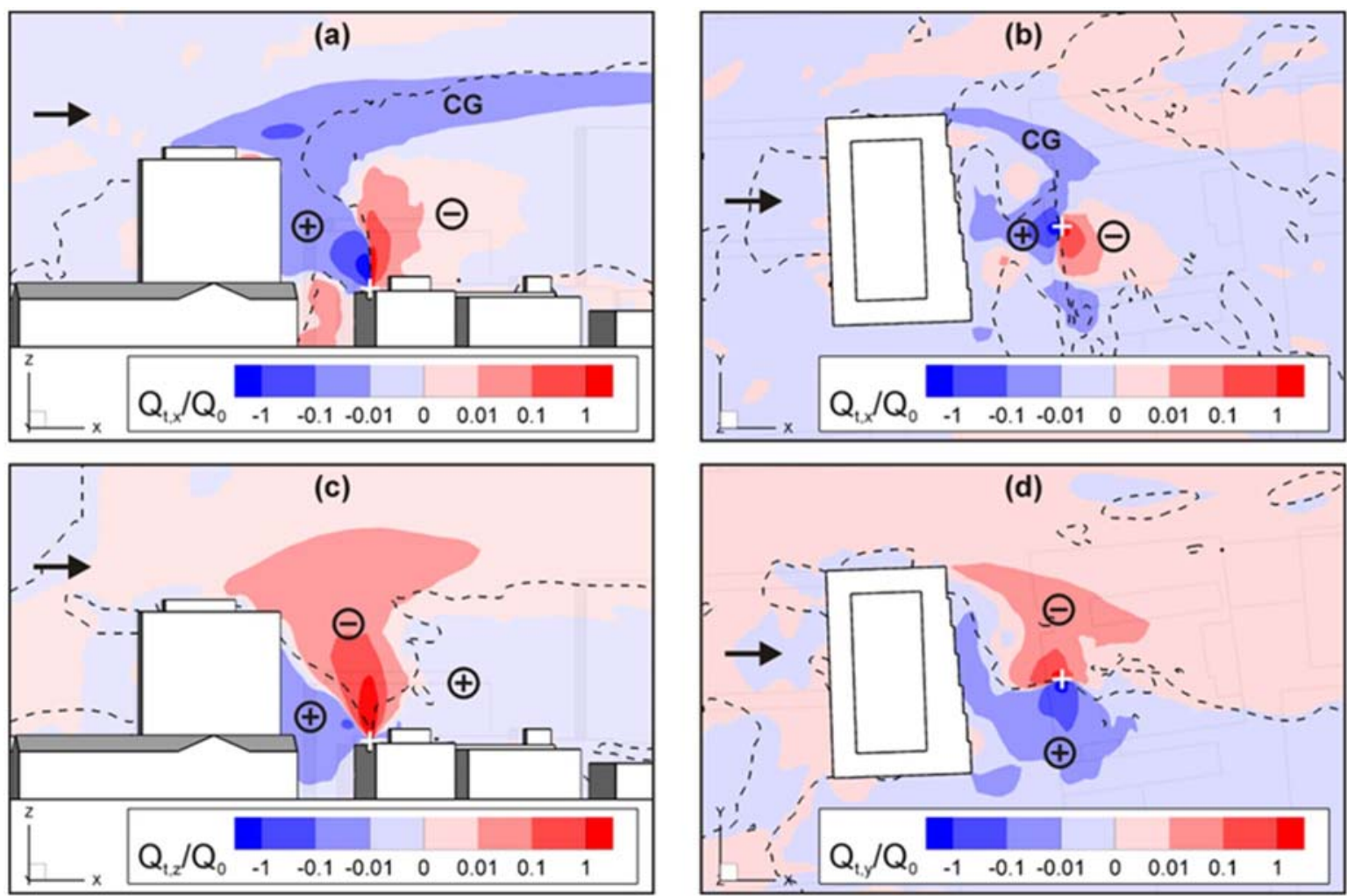

Figure 9. Case SW: contours of the (a,b) streamwise, (c) vertical and (d) lateral components of the nondimensional turbulent mass flux in the planes $(\mathrm{a}, \mathrm{c}) y=y_{\text {stack }}$ and $(\mathrm{b}, \mathrm{d}) z / H=1.47$. The dashed lines represent the isolines $\partial C / \partial x_{i}=0$ in the corresponding direction: $(\mathrm{a}, \mathrm{b}) x_{i}=x,(\mathrm{c}) x_{i}=z,(\mathrm{~d}) x_{i}=y$. On each side of the isoline, the sign of $\partial C / \partial x_{i}$ is indicated in circles ( + positive; - : negative). 

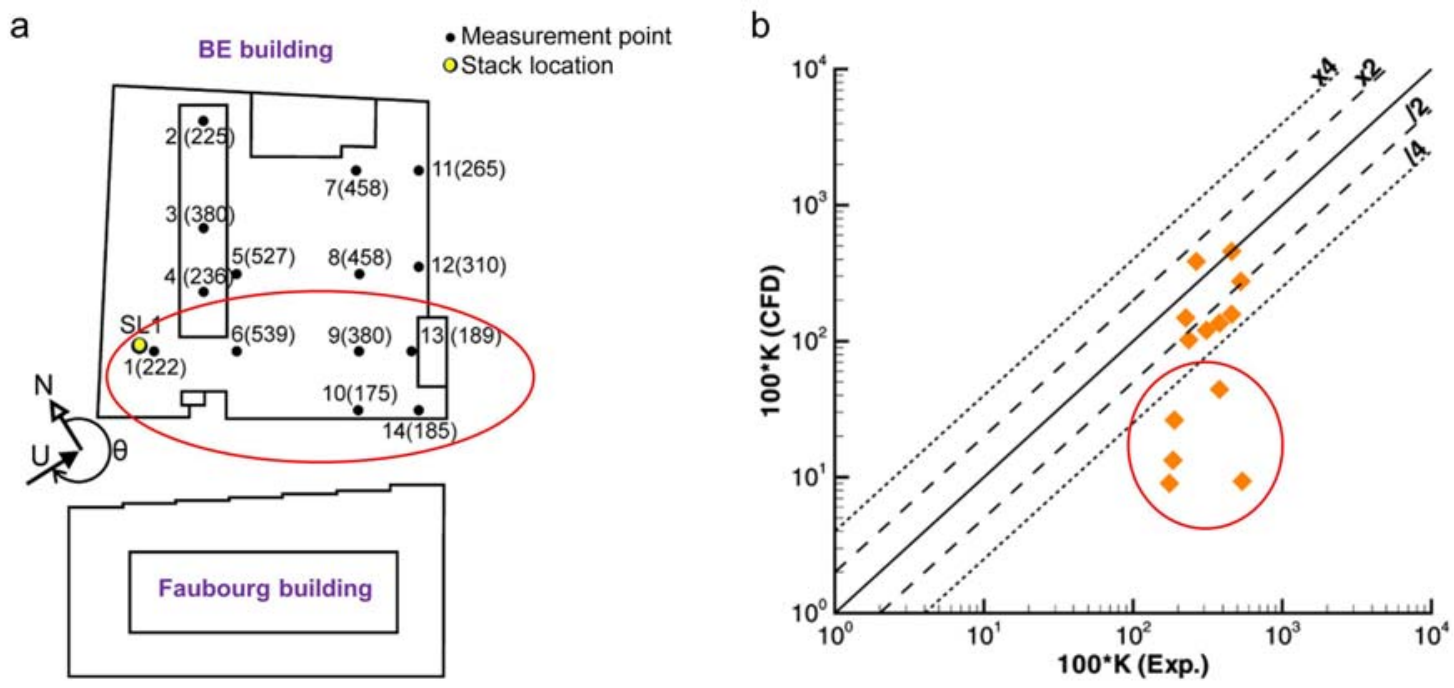

Figure 10. Case W: (a) Top view of BE building and Faubourg building with indication of stack location (SL1), 14 measurement positions and measured values (100K). The positions with least agreement are encircled. (b) Scatter plot of $100 \mathrm{~K}$ values comparing LES with experiments.
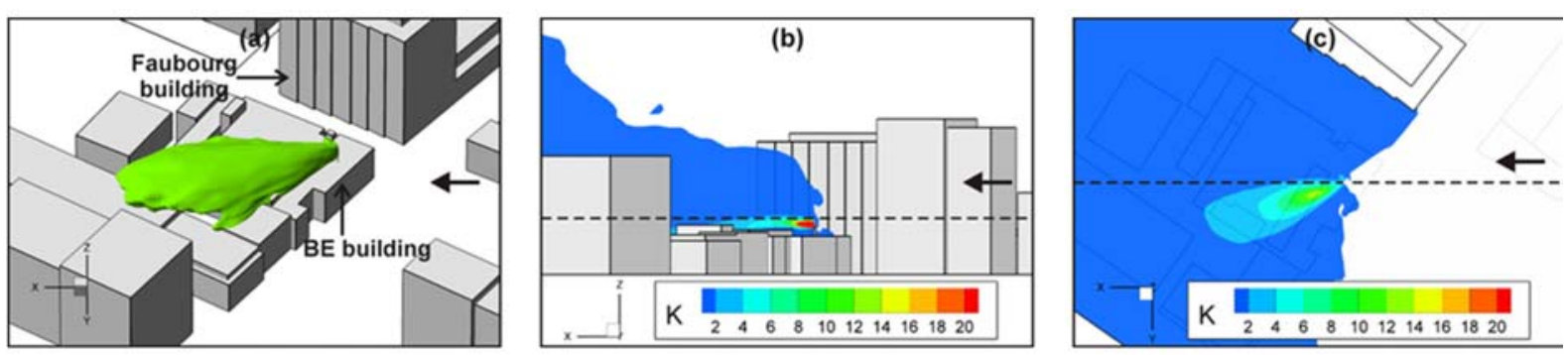

Figure 11. Case W: (a) isosurface $K=1$ and (b,c) contours of the non-dimensional concentration coefficient $K$ in the planes (a) $y=y_{\text {stack }}$ and (b) $z / H=1.47$. The wind direction is indicated by the arrows. The dashed line in (b) indicates the position of the plane shown in (c), and vice versa.
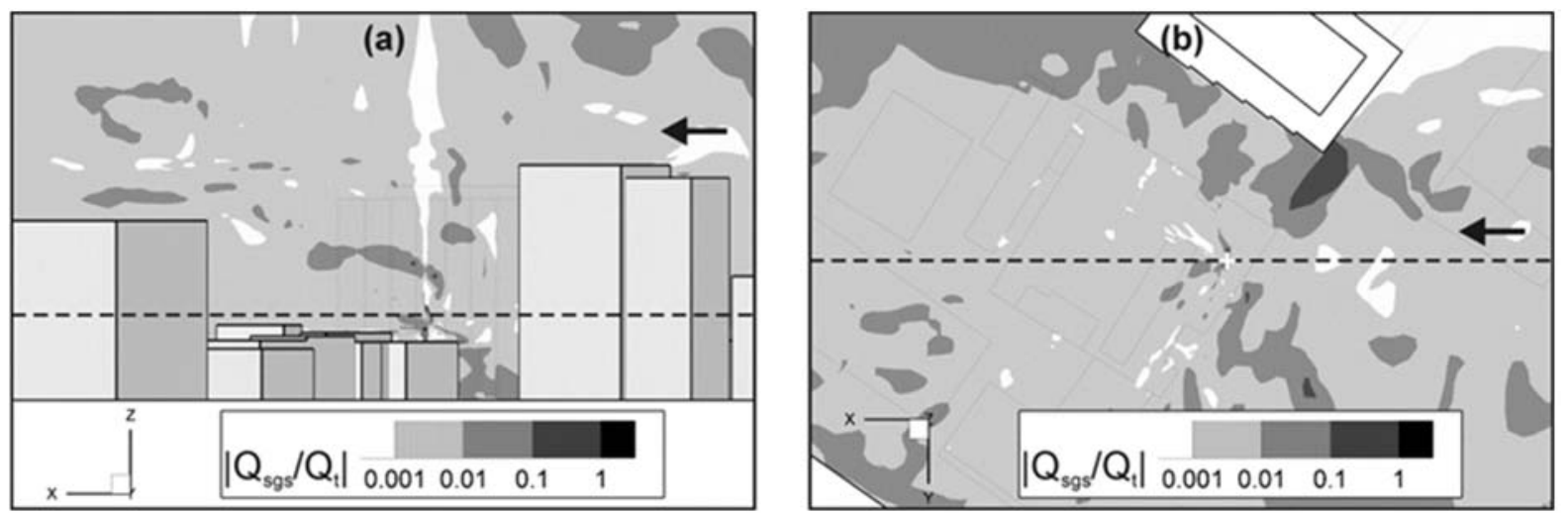

Figure 12. Case W: relative contribution of the SGS mass flux to the total turbulent mass flux. Contours of $\left|Q_{s g s}\right| Q_{t} \mid$ in the planes (a) $y=y_{\text {stack }}$ and (b) $z / H=1.47$. 

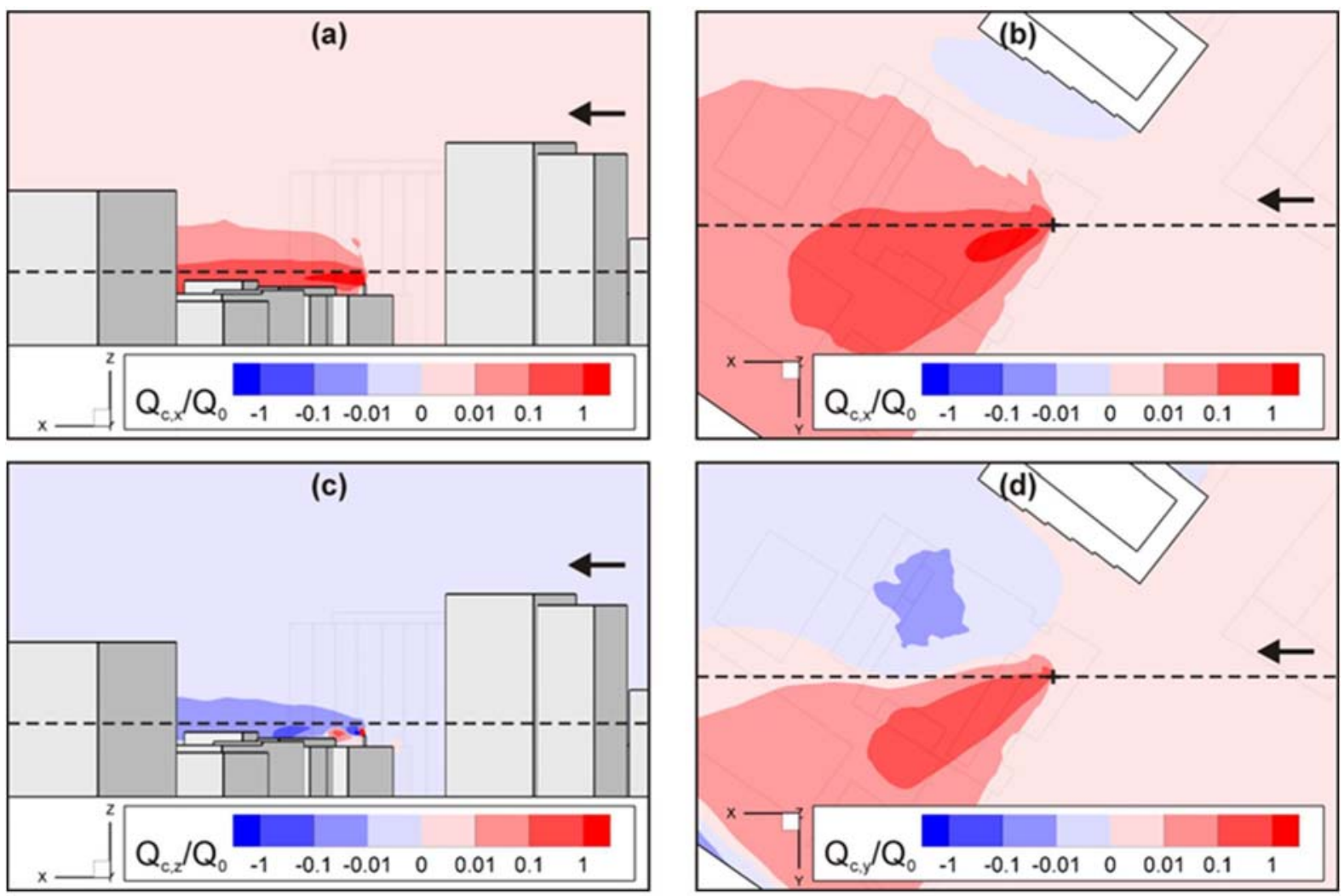

Figure 13. Case W: contours of the $(\mathrm{a}, \mathrm{b})$ streamwise, $(\mathrm{c})$ vertical and $(\mathrm{d})$ lateral components of the nondimensional convective mass flux in the planes (a,c) $y=y_{\text {stack }}$ and $(\mathrm{b}, \mathrm{d}) z / H=1.47$.
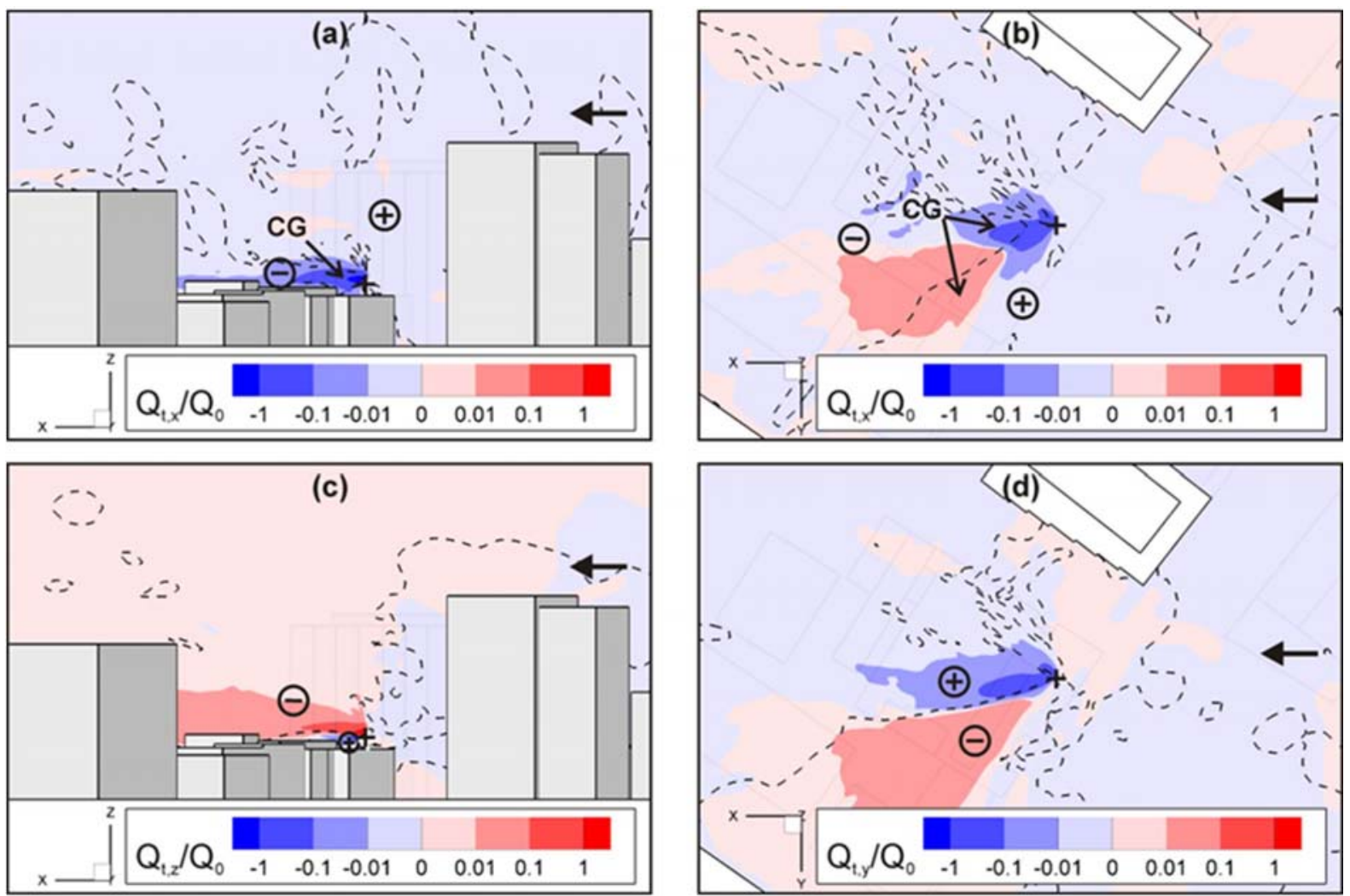

Figure 14. Case W: contours of the $(\mathrm{a}, \mathrm{b})$ streamwise, $(\mathrm{c})$ vertical and $(\mathrm{d})$ lateral components of the nondimensional turbulent mass flux in the planes (a,c) $y=y_{\text {stack }}$ and $(\mathrm{b}, \mathrm{d}) z / H=1.47$. The dashed lines represent the isolines $\partial C / \partial x_{i}=0$ in the corresponding direction: $(\mathrm{a}, \mathrm{b}) x_{i}=x,(\mathrm{c}) x_{i}=z,(\mathrm{~d}) x_{i}=y$. On each side of the isoline, the sign of $\partial C / \partial x_{i}$ is indicated in circles ( + : positive; -: negative). 